\title{
Assessment of Educational Intervention Effects on the Level of Oxidative Stress Parameters and Performance in Oncology Staff
}

\author{
Afsaneh Riazat ${ }^{1}$, Mohammad Esmaeil Akbari ${ }^{2}$, Somayeh Farhang ${ }^{1}$, Sakineh Rakhshanderou ${ }^{3}$, \\ Hamidreza Mirzaei ${ }^{4}$, Payam Azadeh ${ }^{5}$, Mansour Rezazadeh Azari ${ }^{1,6}$ and Davoud Panahi $\mathbb{E}^{1,{ }^{*}}$ \\ ${ }^{1}$ Department of Occupational Health Engineering, School of Public Health and Safety, Shahid Beheshti University of Medical Sciences, Tehran, Iran \\ ${ }^{2}$ Cancer Research Center, Shahid Beheshti University of Medical Sciences, Tehran, Iran \\ ${ }^{3}$ Department of Public Health, School of Public Health and Safety, Shahid Beheshti University of Medical Sciences, Tehran, Iran \\ ${ }^{4}$ Department of Radiotherapy, School of Medicine Shohada-e-Tajrish Hospital, Shahid Beheshti University of Medical Sciences, Tehran, Iran \\ ${ }^{5}$ Department of Radiation Oncology, School of Medicine, Shahid Beheshti University of Medical Science, Tehran, Iran \\ ${ }^{6}$ Safety Promotion and Prevent of Injuries Research Center, School of Public Health, Shahid Beheshti University of Medical Sciences, Tehran, Iran \\ "Corresponding author: Department of Occupational Health Engineering, School of Public Health and Safety, Shahid Beheshti University of Medical Sciences, Tehran, Iran. \\ Email: davodpanahi@gmail.com
}

Received 2021 February 10; Revised 2021 July 20; Accepted 2021 August 04.

\begin{abstract}
Background: Occupational exposure to antineoplastic drugs causes the production of free radicals and their reaction with macromolecules in the body.

Objectives: The present study was conducted to evaluate the effectiveness of the educational intervention by using urinary oxidative stress indices of the oncology staff in Iranian hospitals.

Methods: Healthy full-time oncology and pharmacy staff $(n=45)$ participated in this prospective interventional study. The training of the personnel for proper handling of the antineoplastic drugs was given. During their work shift, their performance was recorded in a checklist. Urinary oxidative stress indices of the staff and scores of their performances were obtained before and after their training.

Results: The mean performance score of all oncology staff was statistically higher than after 2 months of educational intervention $(\mathrm{P}<0.001)$. The mean activity levels of Superoxide Dismutase and Catalase enzymes of all oncology staff was statistically lower than after 2 months of educational intervention $(\mathrm{P}<0.001)$. The mean level of Malondialdehyde of all oncology staff was statistically lower than after 2 months of educational intervention $(\mathrm{P}<0.05)$.

Conclusions: Educational intervention increased oncology staff performance score and it affected the level of the oxidative stress parameters 2 months after the educational intervention by decreasing the activity of enzymes and the level of malondialdehyde.
\end{abstract}

Keywords: Biological Monitoring, Oncology Staff, Educational Interventions, Performance, Stress Oxidative

\section{Background}

Increased cancer screening activity in hospital staff has led to early detection and identification of cancer among them; in this regard, the widespread use of antineoplastic drugs with potent cytotoxic effects has raised concerns about occupational exposure of oncology staff and their health issues (1-3). Due to the length of working hours of the hospital personnel in the oncology unit, they have been exposed to antineoplastic drugs for a long time. Occupational exposure to antineoplastic drugs in different ways, including inhalation, absorption through skin contact during drug preparation or injection, and exposure to human stools have been reported (4-6).

Some antineoplastic drugs, after being absorbed in var- ious ways, can produce oxygen radicals and disrupt the structure of adipose, protein, and cellular DNA $(7,8)$. There are reports of some antineoplastic drugs causing oxidative stress, as well as a variety of diseases such as leukemia, abnormal reproductive activities, spontaneous abortion, cytotoxicity, cancer, and DNA damage in people involved in the preparation and transfer of antineoplastic drugs (3). Exposure to antineoplastic drugs and the consequence of the emergence of oxygen radicals and reaction with body macromolecules such as lipoxygenase (LPX) and protein and DNA can suppress antioxidant enzymes such as superoxide dismutase (SOD) and catalase (CAT), as well as the production of malondialdehyde (MDA), one of the popular secondary products of lipid oxidation after exposure to reactive oxygen species and free radicals in the body (9-11). 
For those working in the health care services, who are exposed to these drugs daily, control measures to reduce staff exposure have been recommended by international organizations such as the Centers for Disease Control (CDC) and the US National Occupational Safety and Health Organization (NIOSH) (12). Protective measures against toxic drugs in dangerous exposures are influenced by individual factors, level of knowledge and awareness of risks, risk perception, use of personal protective equipment, and individual differences (13). Complications of exposure to antineoplastic drugs in the oncology staff are due to a lack of specific knowledge and training in its administration, preparation, and management of antineoplastic drugs (12).

A study has also shown a gap between the knowledge of oncology staff and their actual behavior about the potential risks of carcinogens and the use of protective measures (14). National Institute for Occupational Safety and Health issued the latest guidelines for the protection of personnel against exposure to cytotoxic compounds called "ALERT". This and other guidelines emphasize the importance of training personnel involved with antineoplastic drugs to minimize the risk of exposure to these drugs (15). The goals of education are to raise and create awareness, change attitudes and create healthy attitudes, and ultimately change people's behavior. According to Hazardous Waste Operations and Emergency Response (HAZWOPER) standard, oncology staff must be trained 40 hours a year and have 3 days of field experience at the start of work, and repeat these pieces of training annually (16).

Oxidative stress monitoring in humans can be done indirectly by examining its damage to clinical specimens or by examining the antioxidant potential in tissue or body fluids (17). Therefore, biological monitoring such as monitoring of oxidative stress indices of hospital oncology personnel has been recommended to ensure compliance with safety protocols for treatment with antineoplastic drugs. Biological monitoring can also provide information on the quality of individual occupational health compliance and the effectiveness of control measures such as the use of personal protective equipment (18).

\section{Objectives}

Due to the lack of systematic training and noncompliance with antineoplastic drug safety protocols in Iran and for the lack of credible evidence to support the role of oxidative stress in the etiology of various cancers, this study aimed at evaluating the performance and the effectiveness of the educational intervention on the level of some oxidative stress parameters in oncology staff in Iran.

\section{Methods}

\subsection{Selection of Subjects}

This study is a prospective interventional study conducted in the oncology unit of a hospital in Tehran, Iran, from March to October 2019. The study population was selected from the staff of the oncology department of the hospital according to the principles of the Helsinki Declaration. Sampling was a survey census, including 45 healthy staff, 11 of whom were engaged in drug preparation personnel, 9 general service personnel along with, and 25 nurses participated in the study (Table 1). Subjects were selected from a cohort of 46 oncology staff. Participants should not have been exposed to radiography or chemotherapy in the past 12 months. They should not have thyroid disorders, not be smokers, and eventually, have a year of oncology experience. One male was also excluded because of using thyroid medicine. Before this study, their full consent was obtained. Then, based on the designed questionnaire, the personal characteristics of the personnel and their educational background in dealing with antineoplastic drugs were recorded.

\begin{tabular}{|c|c|}
\hline Professionals & Values \\
\hline Drug preparation & 11 \\
\hline Nurses & 24 \\
\hline Service personnel & 10 \\
\hline \multicolumn{2}{|l|}{ Sex } \\
\hline Men & 11 \\
\hline Women & 34 \\
\hline \multicolumn{2}{|l|}{ Age (women) } \\
\hline Mean $\pm S D(y)$ & $34.68 \pm 5.93$ \\
\hline Range & $24-46$ \\
\hline \multicolumn{2}{|l|}{ Age (men) } \\
\hline Mean $\pm S D(y)$ & $36.82 \pm 9.09$ \\
\hline Range & $29-58$ \\
\hline
\end{tabular}

\subsection{Performance Assessment}

The behavior of 45 personnel exposed to chemotherapy drugs was assessed by a checklist before and 2 months after the intervention. The individual performance checklist that was considered in each of the 28 behaviors was observed and recorded for service personnel groups, nurses, and drug preparation personnel. Completion of the performance checklist was done secretly by the researcher and the presence of the researcher in the process of staff did not interfere. The performance checklists for each study 
group were different and unique. A total of 28 behaviors were collected from medication during the preparation process and drug waste disposal. A checklist was completed 2 months after the intervention. The second checklist was also filled out according to the number assigned to each individual so that it was possible to compare the behavior before and after the intervention of each staff member.

\subsection{Biological Assessment}

Urine samples were taken from participants at the beginning of summer 2019 to measure the enzyme activity of CAT, SOD, and MDA levels. CAT, SOD activities, and MDA levels were measured by a microplate reader ELISA (DANA DA3200 model, Iran manufactured) in urine samples. All stages of urine sample preparation and standard curve drawing and measurement of CAT, SOD enzyme activity, and MDA level were performed according to the instructions provided in the used kits of the Navand Health Company Catalog (NalondiTM kit, Navand Salamat co. UrmiaIran).

The basis of CAT activity measurement is the peroxidative activity of the CAT enzyme in the urine sample. In this reaction, CAT first formaldehyde in the presence of hydrogen peroxide and methanol, and then the resulting formaldehyde, in combination with a chromogen, was measured at $550 \mathrm{~nm}$ by spectroscopy. Based on the standard curve plotted the activity of the CAT enzyme was obtained (19).

Briefly, MDA was measured as a biomarker with Thiobarbituric Acid Reactive Substances (TBARS) Test (20). SOD activity is determined by ELISA microplate reader urine samples and is based on the autooxidation of pyrogallol, a process highly dependent on $\mathrm{O}^{-2}$, the substrate of SOD, and that can be measured spectrophotometrically at 405 $\mathrm{nm}$. In the presence of SOD, pyrogallol autooxidation is inhibited so that the activity of the enzyme can be measured indirectly. SOD activity assay was performed, using the NalondiTM kit (Navand Salamat Co. Urmia-Iran) (19).

\subsection{Training Intervention}

The intervention of proper training on how to work with antineoplastic drugs and taking on-the-job safety measures, based on guidelines provided by the NIOSH and the American Community Health System (ASHP) pharmacists $(21,22)$. The educational program was designed for 3 educational groups (nurses, drug preparation personnel, and service personnel) according to their activity and level of education. And educational pamphlets were used. According to Table 2, training sessions consisted of 3 lecture sessions with 2-hour question-and-answer sessions with instructional videos and slides, face-to-face training, and leaflets in each hospital for 3 consecutive weeks.

Finally, after 2 months, these parameters were measured and recorded again.

\subsection{Statistical Analysis}

To evaluate the effect of educational intervention on performance, the activity of CAT, SOD, and MDA levels of nurses and drug preparation personnel and service personnel in each hospital, SPSS software 21 was used. After collecting the data, Kolmogorov-Smirnov and Shapiro-Wilk tests were used to determine their normality. Then, due to the normality of the data, a paired-sample $t$ test was used to compare the mean of the data obtained before and after the educational intervention to prove the significant effect of the educational intervention on them.

\subsection{Ethical Considerations}

The study was approved by the Research Ethics Committee of Shahid Beheshti University of Medical Sciences, Tehran, Iran (IR.SBMU.PHNS.REC.1397.116). Informed consent was obtained from all participants and each one received a code to be unknown.

\section{Results}

The main characteristics of the oncology staff exposed to antineoplastic drugs are shown in Table 1 . The results (mean \pm standard deviation) of the analyses of the score of performance, CAT enzyme activity, SOD enzyme activity, and MDA level are shown in Tables 3 - 6.

\subsection{Performance of Group}

The educational intervention increased the performance score of oncology staff and most of the performance after the educational intervention was under the guidelines for working with antineoplastic drugs. The educational intervention increased the performance of nurses, drug preparation personnel, and service personnel by $7.16,11$, and 9.20, respectively. According to Table 3 , there was a significant difference between the mean scores of oncology staff exposure to antineoplastic drugs before and 2 months after the educational intervention $(\mathrm{P}<0.001)$.

\subsection{Analysis of Oxidative Stress Parameters}

According to Table 4, the difference between the mean score of CAT activity before and after the intervention was $11.49(\mathrm{nmol} / \mathrm{mL})$ for nurses, $12.86(\mathrm{nmol} / \mathrm{mL})$ for drug preparation personnel, and $11.62(\mathrm{nmol} / \mathrm{mL})$ for service personnel. Since the level of significance $(\mathrm{P}<0.001)$ in all groups 


\begin{tabular}{|c|c|c|c|c|}
\hline Row & Educational Group & Educational Subject & Teaching Method & $\begin{array}{c}\text { Number of } \\
\text { Training Sessions }\end{array}$ \\
\hline $\mathbf{1}$ & Nurses & $\begin{array}{l}\text { Introduction, nurses' exposure potential, } \\
\text { ways of exposure, exposure conditions, } \\
\text { effects of exposure, existing standards and } \\
\text { recommendations, case reports, } \\
\text { supplementary recommendations, } \\
\text { prescribing high-risk drugs, and } \\
\text { summarizing the above }\end{array}$ & $\begin{array}{l}\text { Lecture with slides and questions and } \\
\text { answers, showing educational videos, give } \\
\text { pamphlets }\end{array}$ & 3 \\
\hline 2 & Drug preparation & $\begin{array}{l}\text { Introduction, drug preparation' exposure } \\
\text { potential, ways of exposure, exposure } \\
\text { conditions, effects of exposure, existing } \\
\text { standards and recommendations, case } \\
\text { reports, supplementary } \\
\text { recommendations, prescribing high-risk } \\
\text { drugs and summarizing the above }\end{array}$ & $\begin{array}{l}\text { Lecture with slides and questions and } \\
\text { answers, showing educational videos, give } \\
\text { pamphlets }\end{array}$ & 3 \\
\hline 3 & Service personnel & $\begin{array}{l}\text { Introduction, service personnel' exposure } \\
\text { potential, ways of exposure, exposure } \\
\text { conditions, effects of exposure, existing } \\
\text { standards and recommendations, case } \\
\text { reports, supplementary } \\
\text { recommendations, prescribing high-risk } \\
\text { drugs and summarizing the above }\end{array}$ & $\begin{array}{l}\text { Lecture with slides and questions and } \\
\text { answers, showing educational videos, give } \\
\text { pamphlets }\end{array}$ & 3 \\
\hline
\end{tabular}

\begin{tabular}{|lcl}
\hline Table 3. Mean Score of Oncology Staff Performance Before and After Educational Intervention Group Oncology Staff Performance \\
\hline Measuring Steps & Mean \pm SD & \\
\hline Nurses(n=24) & $13.12 \pm 3.66$ \\
\hline Before educational intervention & $20.29 \pm 4.02$ \\
\hline After educational intervention & \\
\hline Drug preparation $(\mathbf{n}=\mathbf{1 1})$ & $13.09 \pm 3.36$ \\
\hline Before educational intervention & $24.09 \pm 3.04$ \\
\hline After educational intervention & $<.001$ \\
\hline service personnel (n= 10) & $10.60 \pm 3.53$ \\
\hline Before educational intervention & $19.80 \pm 3.35$ \\
\hline After educational intervention & $<.001$ \\
\hline
\end{tabular}

Table 4. Mean Level of Oncology Staff CAT (nmol/mL) Enzyme Activity Before and After Educational Intervention

\begin{tabular}{lcc}
\hline \multirow{2}{*}{ Groups/Measuring Step } & Oncology Staff CAT (nmol/mL) Enzyme Activity \\
\cline { 2 - 3 } Nurses $(\mathbf{n}=\mathbf{2 4})$ & Mean \pm SD & \\
\hline Before educational intervention & $25.80 \pm 7.22$ \\
\hline After educational intervention & $14.31 \pm 9.03$ \\
\hline Drug preparation $(\mathbf{n}=\mathbf{1 1})$ & \\
\hline Before educational intervention & $33.59 \pm 10.39$ \\
\hline After educational intervention & $20.72 \pm 12.67$ \\
\hline Service personnel (n) $\mathbf{1 0})$ & \\
\hline Before educational intervention & $24.68 \pm 11.31$ \\
\hline After educational intervention & $13.06 \pm 10.15$ \\
\hline
\end{tabular}


Riazat A et al.

\begin{tabular}{|c|c|c|}
\hline \multirow{2}{*}{ Groups/Measuring Step } & \multicolumn{2}{|c|}{ Oncology Staff SOD $(\mathrm{U} / \mathrm{mL})$ Enzyme Activity } \\
\hline & Mean \pm SD & Significance Level $(P)$ \\
\hline Nurses $(n=24)$ & & 0.001 \\
\hline Before educational intervention & $159.81 \pm 15.17$ & \\
\hline After educational intervention & $145.54 \pm 15.25$ & \\
\hline Drug preparation $(\mathbf{n}=\mathbf{1 1})$ & & 0.001 \\
\hline Before educational intervention & $164.30 \pm 14.96$ & \\
\hline After educational intervention & $151.70 \pm 18.46$ & \\
\hline Service personnel $(\mathbf{n}=\mathbf{1 0})$ & & 0.001 \\
\hline Before educational intervention & $161.69 \pm 16.55$ & \\
\hline After educational intervention & $148.01 \pm 14.57$ & \\
\hline \multirow{2}{*}{ Groups/Measuring Step } & \multicolumn{2}{|c|}{ Oncology Staff MDA (nmol/mL) } \\
\hline & Mean \pm SD & Significance Level $(P)$ \\
\hline Nurses $(\mathbf{n}=\mathbf{2 4})$ & & 0.05 \\
\hline Before educational intervention & $114.45 \pm 36.54$ & \\
\hline After educational intervention & $108.81 \pm 35.51$ & \\
\hline Drug preparation $(n=11)$ & & 0.05 \\
\hline Before educational intervention & $198.24 \pm 58.75$ & \\
\hline After educational intervention & $188.80 \pm 56.81$ & \\
\hline Service personnel $(\mathrm{n}=10)$ & & 0.05 \\
\hline Before educational intervention & $98.57 \pm 25.91$ & \\
\hline After educational intervention & $90.74 \pm 23.19$ & \\
\hline
\end{tabular}

of nurses, drug preparation personnel, and service personnel were less than the level of error $(\alpha=0.05)$ Therefore, the difference between the mean score of CAT enzyme activity level before and after the educational intervention was significant.

The difference between the mean score of SOD enzyme activity before and after the educational intervention was $14.26(\mathrm{U} / \mathrm{mL})$ in nurses, $12.60(\mathrm{U} / \mathrm{mL})$ in drug preparation personnel, and $13.68(\mathrm{U} / \mathrm{mL})$ in-service personnel. According to Table 5 , there was a significant difference between the mean scores of SOD enzyme activity before and 2 months after the educational intervention in oncology staff $(\mathrm{P}<0.001)$ (Table 4$)$.

According to Table 6, the difference between the mean score of MDA level before and after the intervention was $5.64(\mathrm{nmol} / \mathrm{mL})$ for nurses, $9.43(\mathrm{nmol} / \mathrm{mL})$ for drug preparation personnel, and $7.83(\mathrm{nmol} / \mathrm{mL})$ for service personnel. The level of significance in the groups of nurses, drug preparation personnel, and service personnel was smaller than the level of error level considered ( $\alpha=0.05)$; so, the difference between the mean MDA level was significant before and after the educational intervention $(\mathrm{P}<0.05)$. The mean level of MDA was statistically lower than after 2 months of educational intervention.

\section{Discussion}

The chemotherapy drugs used to treat cancer cannot detect the difference between cancer cells and normal cells, which can lead to impaired growth and function of both healthy and diseased cells, as a result, toxic effects occur for both treated patients and healthcare workers (23). Oncology staff needs specialized knowledge and skills to ensure patient safety, as well as their safety (7). In studies of Gómez-Oliván et al. and Rombaldi et al., the activity of CAT and SOD enzymes was significantly increased compared to the control group, indicating that the oncology staff was at risk for antineoplastic drugs. Studies show the usefulness of oxidative stress assessment in oncology staff over other biological assessments, such as genotoxic 
risk assessment because both events often result from the same factors $(3,7)$. Due to the lack of systematic training and non-compliance with antineoplastic drug safety protocols in Iran, this study aimed at evaluating the effectiveness of the educational intervention on the level of some oxidative stress parameters in oncology staff in Iran. Our study showed that oncology staff, who have received training on how to work with antineoplastic drugs, have performed similarly to international guidelines. We also showed that educational intervention affected the level of some oxidative stress parameters in oncology staff. In studies of Al-Ghamdi (24) and Chaudhary (25) as in our study, the mean score of oncology staff performance before educational intervention based on the performance checklists showed non-compliance with NIOSH guidelines and training videos provided by the Canadian Pharmacists Association. In this study, the educational intervention increased the performance score mean of oncology staff like the study of Mahdy et al. to evaluate the effect of cytotoxic drugs safe-handling guidelines on nurses' performance (26). In this study, most of the performance after the educational intervention was under the guidelines for working with antineoplastic drugs. The educational intervention had a significant effect on the enzyme activities of CAT, SOD, and MDA level, which was not found in other studies similar to this study.

The decrease in MDA, SOD, and CAT is due to the following lessons learned: (1) individual workplace hazard assessment that includes the evaluation of equipment (such as ventilator/cabin, isolation systems, gloves, needle-free systems, and personal protective equipment), the physical layout of the workplace, type of medication, volume, frequency, and shape of drugs used (tablets, coated and uncoated drugs, powder, liquid, etc.), equipment maintenance, cleaning and disinfection, waste treatment, potential occupational exposure to high-risk drugs, blood pathogens, inactive chemicals manufacturing of high-risk medicines or cleaning surfaces contaminated with drugs, routine operations, actions during spills or mess, waste segregation, containment and disposal of antineoplastic drugs and equipment; (2) determining specific policies and procedures for working safely with anti-neoplastic drugs such as labeling of high-risk drugs, drug storage, staff-related problems (such as exposure of pregnant workers), leakage and drug spillage control, precise and detailed procedures for preparation, prescription disposal of high-risk drugs; (3) use and maintenance of equipment properly.

\subsection{Conclusions}

At least in this study, the educational intervention increased the staff performance of oncology score and it af- fected the level of the oxidative stress parameters 2 months after the educational intervention by decreasing the activity of enzymes and the level of MDA. Due to time and cost constraints, the control group was not considered and examined only the effect of training on some parameters of oxidative stress in oncology personnel before and after the intervention. It is suggested that further studies be performed on the biological monitoring of oncology staff by evaluating drugs, their metabolites, and exposure effects.

\section{Footnotes}

Authors' Contribution: A. R, implemented trial, acquired data, performed the experiments, data analysis and interpretation, literature search, and drafted initial manuscript; M. E. A, M. R. A, D. P, H. R. M and P. A, developed study concept and contributed towards study design, data interpretation, and helped in revising the manuscript; S. F, D and S, S. R, contributed towards study design, data analysis, and interpretation, and manuscript review. All authors have approved the final version of the manuscript for submission.

Conflict of Interests: The authors have declared that no competing interests exist

Ethical Approval: The study was approved by the Research Ethics Committee of Shahid Beheshti University of Medical Sciences, Tehran, Iran (IR.SBMU.PHNS.REC.1397.116).

Funding/Support: The authors are grateful to the Shahid Beheshti University of Medical Sciences for their financial support. This study was supported by the Shahid Beheshti University of Medical Sciences (grant No. 17989).

Informed Consent: Informed consent was obtained from all participants and each one received a code to be unknown.

\section{References}

1. Constantinidis TC, Vagka E, Dallidou P, Basta P, Drakopoulos V, Kakolyris S, et al. Occupational health and safety of personnel handling chemotherapeutic agents in Greek hospitals. Eur J Cancer Care. 2011;20(1):123-31. doi: 10.1111/j.1365-2354.2009.01150.x. [PubMed: 20148939].

2. Panahi D, Azari M, Akbari ME, Zendehdel R, Mirzaei HR, Hatami H, et al. Development of a new method for sampling and monitoring oncology staff exposed to cyclophosphamide drug. Environ Monit Assess. 2016;188(4):238. doi: 10.1007/s10661-016-5255-x. [PubMed: 27003403].

3. Gomez-Olivan LM, Miranda-Mendoza GD, Cabrera-Galeana PA, GalarMartinez M, Islas-Flores H, Sanjuan-Reyes N, et al. Oxidative stress induced in nurses by exposure to preparation and handling of antineoplastic drugs in Mexican hospitals: A multicentric study. Oxid Med Cell Longev. 2014;2014:858604. doi: 10.1155/2014/858604. [PubMed: 24719678]. [PubMed Central: PMC3956419]. 
4. Vyas N, Yiannakis D, Turner A, Sewell GJ. Occupational exposure to anti-cancer drugs: A review of effects of new technology. $J$ Oncol Pharm Pract. 2014;20(4):278-87. doi: 10.1177/1078155213498630. [PubMed: 23975555].

5. Martin Lancharro P, De Castro-Acuna Iglesias N, Gonzalez-Barcala FJ, Moure Gonzalez JD. Evidence of exposure to cytostatic drugs in healthcare staff: A review of recent literature. Farm Hosp. 2016;40(n06):604-21. doi: 10.7399/fh.2016.40.6.9103. [PubMed: 27894231].

6. Kibby T. A review of surface wipe sampling compared to biologic monitoring for occupational exposure to antineoplastic drugs. J Occup Environ Hyg. 2017;14(3):159-74. doi: 10.1080/15459624.2016.1237026. [PubMed: 27676216].

7. Rombaldi F, Cassini C, Salvador M, Saffi J, Erdtmann B. Occupational risk assessment of genotoxicity and oxidative stress in workers handling anti-neoplastic drugs during a working week. Mutagenesis. 2009;24(2):143-8. doi: 10.1093/mutage/gen060. [PubMed: 19011124].

8. Azari MR, Akbari ME, Abdollahi MB, Mirzaei HR, Sahlabadi AS, Tabibi R, et al. Biological monitoring of the oncology healthcare staff exposed to cyclophosphamide in two hospitals in Tehran. Int J Cancer Manag. 2019;12(1). e86537.

9. Sohal RS. Role of oxidative stress and protein oxidation in the aging process. Free Radic Biol Med. 2002;33(1):37-44. doi: 10.1016/s08915849(02)00856-0. [PubMed: 12086680].

10. Singh U, Jialal I. Oxidative stress and atherosclerosis. Pathophysiology. 2006;13(3):129-42. doi: 10.1016/j.pathophys.2006.05.002. [PubMed: 16757157].

11. Drury JA, Nycyk JA, Cooke RW.Comparison of urinary and plasma malondialdehyde in preterm infants. Clin Chim Acta. 1997;263(2):177-85. doi:10.1016/s0009-8981(97)00051-x. [PubMed: 9246422].

12. Power LA, Polovich M. Safe handling of hazardous drugs: Reviewing standards for worker protection. New York, USA: McMahon Publishing; 2012. $11 \mathrm{p}$.

13. Polovich M. Nurses' use of hazardous drug safe handling precautions [dissertation]. Atlanta, Georgia: Georgia State University; 2019.

14. Ben-Ami S, Shaham J, Rabin S, Melzer A, Ribak J. The influence of nurses' knowledge, attitudes, and health beliefs on their safe behavior with cytotoxic drugs in Israel. Cancer Nurs. 2001;24(3):192-200. [PubMed: 11409063].

15. Connor TH, Burroughs GE, McDiarmid MA, Mead KR, Power LA, Reed LD. NIOSH Alert: Preventing occupational exposures to antineoplastic and other hazardous drugs in health care settings. Atlanta, Georgia: DHHS (NIOSH) Publication; 2004.

16. Momeni M, Danaei M, Askarian M. How do nurses manage their occupational exposure to cytotoxic drugs? A descriptive survey in chemotherapy settings, Shiraz, Iran. Int J Occup Environ Med. 2013;4:102-6.

17. Maurya PK, Chandra P. Oxidative stress: Diagnostic methods and applications in medical science. Singapore: Springer; 2017. doi: 10.1007/978981-10-4711-4.

18. Wilson HK. Biological monitoring values for occupational exposure: A United Kingdom perspective. Int Arch Occup Environ Health. 1999;72(4):274-8. doi: 10.1007/s004200050373. [PubMed: 10491784].

19. Tajaldini M, Samadi F, Khosravi A, Ghasemnejad A, Asadi J. Protective and anticancer effects of orange peel extract and naringin in doxorubicin treated esophageal cancer stem cell xenograft tumor mouse model. Biomed Pharmacother. 2020;121:109594. doi: 10.1016/j.biopha.2019.109594. [PubMed: 31707344].

20. Khadem Ansari MH, Hamzyan Olia JB, Yaghmaei P, Ayatollahi H, Khalkhali HR. Evaluation of oxidative stress marker in patients with human papillomavirus infection. Ann Trop Med Public Health. 2017;10(6):1518. doi:10.4103/atmph.atmph_464_17.

21. NIOSH Alert. Preventing occupational exposures to antineoplastic and other hazardous drugs in health care settings. Columbia, USA: NIOSH Publications; 2004. Available from: https://www.cdc.gov/NIOSH/ DOCS/2004-165/pdfs/2004-165sum.pdf.

22. Power LA, Coyne JW. ASHP guidelines on handling hazardous drugs. Am J Health Syst Pharm. 2018;75(24):1996-2031. doi:10.2146/ajhp180564. [PubMed: 30327293].

23. Azari M, Panahi D, Akbari ME, Mirzaei HR, Rezvani HR, Zendehdel $\mathrm{R}$, et al. Environmental monitoring of occupational exposure to cyclophosphamide drug in two Iranian hospitals. Int J Cancer Manag. 2017;10(1). e7229.

24. Al-Ghamdi MS, Al-Mustafa ZH. The handling of anticancer drugs in Riyadh and the Eastern Province. Ann Saudi Med.1997;17(2):257-9. doi: 10.5144/0256-4947.1997.257. [PubMed: 17377446].

25. Chaudhary R, Karn BK. Chemotherapy-knowledge and handling practice of nurses working in a medical university of Nepal.J Cancer Ther. 2012;3(1):110-4. doi: 10.4236/jct.2012.31014.

26. Mahdy NE, Rahman AARA, Hassan HA. Cytotoxic drugs safety guidelines: Its effect on awareness and safe handling practices of oncology nurses. IOSR J Nurs Health Sci. 2017;6(3):22-33. doi: 10.9790/19590603032233. 